Article

\title{
Bitumen Recovery from Crude Bitumen Samples from Halfaya Oilfield by Single and Composite Solvents-Process, Parameters, and Mechanism
}

\author{
Yunfeng Liu ${ }^{1, *}$, Zhengsong Qiu ${ }^{1, *}$, Hanyi Zhong ${ }^{1}$, Zhen $\mathrm{Nie}^{2}$, Jia Li ${ }^{1}$, Weian Huang ${ }^{1}$ and \\ Xin Zhao ${ }^{1}$ \\ 1 School of Petroleum Engi neering, China University of Petroleum (East China), Qingdao 266580, China \\ 2 China National Petroleum Corporation (CNPC) Research Institute of Petroleum Exploration and \\ Development, Beijing 100083, China \\ * Correspondence: b15020047@s.upc.edu.cn (Y.L.); qiuzs@upc.edu.cn (Z.Q.); Tel.: +86-13070844389 (Y.L.)
}

Received: 2 August 2019; Accepted: 18 August 2019; Published: 21 August 2019

\begin{abstract}
Since 2007, heterogeneous, high-viscosity active bituminous formations have often occurred during the drilling process in Yadavaran oilfield (Iran), Halfaya oilfield (Iraq), and tar sands (Canada). The formation of bitumen exhibits plastic and creep properties, and its adhesion is strong, so drilling accidents are easily caused, such as adhering vibrating screen, drill pipe sticking, lost circulation, and even well abandonment. These complex problems cause huge economic losses. Solvents used to dissolve bitumen are a feasible technology to remove bitumen effectively. In order to solve this problem, we used crude bitumen samples from Halfaya oilfield to study the relation between the bitumen component and different solvents. In this study, the temperature, crude bitumen sample to solvent ratio, stirring rate, stirring time, and ultrasound time on bitumen recovery by toluene were investigated by a single factor experiment. The optimum process parameter for bitumen recovery was obtained. Toluene, n-heptane, tetrahydrofuran, cyclohexane, cyclopentane, ethyl acetate, and $\mathrm{n}$-pentane were chosen as the solvents for single solvent extraction and composite solvent extraction. The bitumen recovery increased significantly with the use of a composite solvent compared to a single solvent. The composite solvent ratio was 1:1. The highest bitumen recovery was $98.9 \mathrm{wt} \%$ by toluene/cyclohexane composite solvent. The SARA (saturates, aromatics, resins, and asphaltenes) components of the bitumen were analyzed. The toluene showed the highest asphaltene content, while the n-alkanes showed the lowest asphaltene content. The higher the asphaltene content, the higher the bitumen recovery. The composite solvent obtained the highest asphaltene content and bitumen recovery. The viscosity of bitumen extraction by different solvents was measured. The lower the bitumen viscosity, the higher the bitumen recovery. The element analysis indicated the solvent's ability to extract bitumen colloids with the $\mathrm{C} / \mathrm{H}$ ratio. This study provides a reliable theoretical basis for the subsequent adoption of effective anti-bitumen polluted drilling fluid additives.
\end{abstract}

Keywords: bitumen recovery; solvent extraction; SARA analysis; composite solvent

\section{Introduction}

Since 2007, heterogeneous and active bituminous formations have been encountered in the development of Yadavaran oilfield in Iran, Halfaya oilfield in Iraq, the deep-water oilfield in the Gulf of Mexico, the tar sands in Canada, etc. [1-6]. Bituminous formations have plastic and creep properties, and the bitumen adhesion property is always strong (Figure 1). This property can easily cause several safety accidents, such as viscose vibrating screen, drilling pipe sticking, lost circulation, and even well abandonment. 

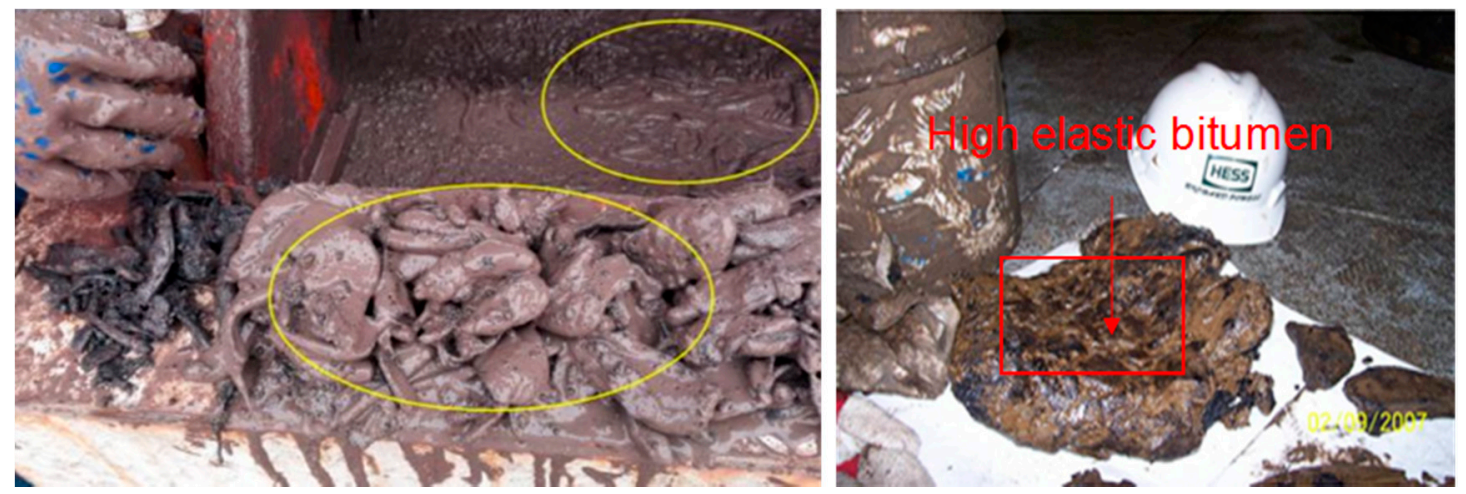

Figure 1. Typical formation of bitumen drilled in the oil-gas drilling process.

Considering the complexities in the drilling process for bituminous formations, drilling engineers often take some technical measures, including increasing the density of drilling fluids, adding diesel and emulsifiers, partially replacing the contaminated pulp, or combining chemical plugging [7].

Through investigating the influence of drilling fluid (contaminated by the formation of bitumen) performance (Figure 2), it was shown that bitumen formation on drilling fluid caused the rheological properties of bitumen to deteriorate seriously. Moreover, the viscosity increased significantly and the energy consumption increased significantly. As was shown in Figure 2, the bitumen density varied greatly, which affected the drilling fluid circulation, and could well kick and leak occurrences. The bitumen caused the lubrication performance to deteriorate, and could even cause the drill pipe to break. The bitumen pollution made the next operation process difficult, and the harm caused is more serious than water pollution [8].

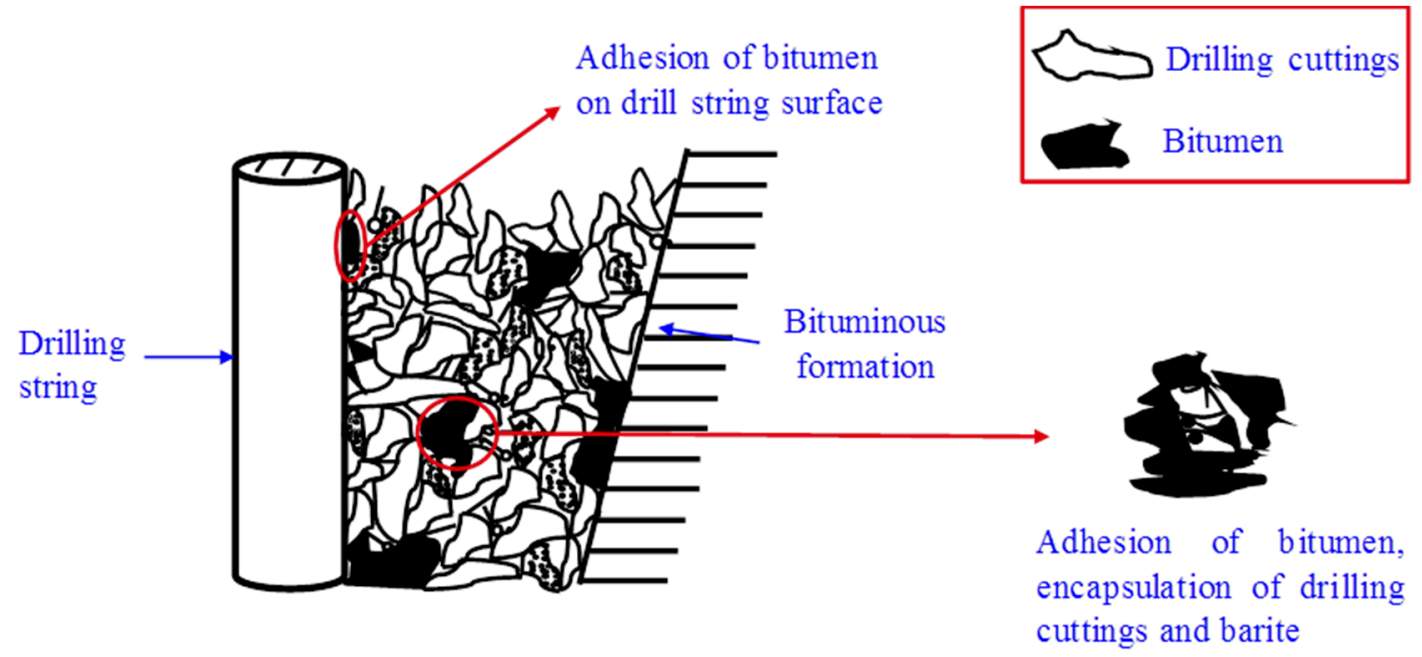

Figure 2. Schematic diagram of the formation of bitumen pollution and the sticking mechanism.

Therefore, it is important to find methods to remove formation bitumen. The solvent extraction of bitumen proved to be an important method to remove bitumen. Research was mainly concentrated on the oil sands separation process.

Oil sands are significant unconventional oils $[9,10]$, and the utilization of unconventional oil is a hot research issue [11]. The methods of obtaining bitumen from oil sands consist of the hot water-based extraction (HWBE) process [12-15], the solvent extraction process [16,17], and pyrolysis [18-21]. Emulsion is usually used in the oil sands separation or enhanced oil recovery (EOR) processes [22-25]. Oil sands are categorized as oil-wet, water-wet, and neuter-wet. The HWBE process is only suitable for water-based oil sands and not suitable for oil-wet sands [26]. The HWBE process has many 
disadvantages, such as high energy consumption and environmental pollution. Bitumen recovery by solvent extraction shows more advantages than the HWBE process.

Due to the differences between oil sands and crude bitumen samples from Halfaya oilfield (Iraq), the conclusions reached from oil sands solvent extraction were not suitable for crude bitumen; therefore, crude bitumen samples from Halfaya oilfield (Iraq) were chosen for the solvent extraction process and the mechanism that guides the bitumen removal process.

Although many research studies have focused on the operational parameters of bitumen recovery, they were incomplete. Bitumen can be divided into four SARA (saturates, aromatics, resins, and asphaltenes) components, which are different in polarity, solubility, density, and molecular weight $[10,27,28]$. The relationship between SARA content and bitumen recovery is unclear; therefore, exploring the relationship between SARA content and bitumen recovery is important to optimizing the bitumen recovery process.

Many researchers have focused on the mechanical properties of asphaltic materials, which constitute a significant issue for the application of bitumen in pavement design. Bazzaz put forward a procedure to characterize the nonlinear viscoelastic response of asphalt concentration at high temperatures [29]. Darabi put forward a coupled nonlinear viscoelastic (VE)- viscoplastic(VP)hardening-relaxation(HR) model and proposed a systematic analysis procedure to study the nonlinear viscoelastic-viscoplastic with a hardening-relaxation constitutive relationship for asphalt mixtures [30]. In this paper, we focused on the viscosity of bitumen from different extraction processes, the relationship between bitumen viscosity and bitumen recovery, and the mechanical properties of bitumen.

Previous studies have focused on a single solvent to extract bitumen from oil sands, with most research works focused on toluene's role in bitumen recovery from oil sands. Toluene has many disadvantages; it is toxic, flammable, and causes harm to the surroundings. Therefore, finding other low-toxic solvents is a vital issue for researchers. We studied the role of different solvents on the bitumen recovery from crude bitumen samples taken from Halfaya oilfield (Iraq). The composite solvent was designed to study the effect on bitumen recovery from crude bitumen samples.

In this study we explored the bitumen role with different solvents, in order to further solve the problem of bitumen sticking. Besides, we obtained the optimal operation parameters for bitumen recovery from crude bitumen samples by toluene extraction. In the end, we identified the bitumen recovery and SARA of single solvent extraction and composite solvent extraction.

\section{Materials and Methods}

\subsection{Chemicals and Samples}

Toluene, n-heptane, tetrahydrofuran, cyclohexane, cyclopentane, ethyl acetate, n-heptane, methanol, and trichloroethylene were of analytical grade and were purchased from Qingdao Baoze Technology Co. Ltd., Qingdao, China. The crude bitumen samples were from Halfaya oilfield (Iraq) (23.8 $\mathrm{wt} \%$ sands).

\subsection{Single Factor Experiment}

The solvent extraction conditions were optimized using single factor experiments. Temperature, crude bitumen sample to solvent ratio, stirring rate, stirring time, and ultrasound time were the parameters for bitumen recovery from the crude bitumen samples.

The detailed experiment procedure is documented in Tables 1 and 2. Table 1 shows the experimental conditions for single solvent extraction. The other factors in Table 1 are explained in detail in Table 2. First, $2.5 \mathrm{~g}$ of crude bitumen samples and $50 \mathrm{~mL}$ of toluene were weighed and put into a $200 \mathrm{~mL}$ beaker. The beaker was then put into a water bath at the set temperature, which was agitated in a magnetic blender. After the stirring process, the mixture was centrifuged at $7000 \mathrm{rpm}$ for $15 \mathrm{~min}$, and the supernatant was transferred into a flask. The solvent was removed by a rotary evaporator and 
the bitumen was oven-dried and then weighed. Similar experiment procedures were repeated twice. The third extraction was the final bitumen recovery.

Table 1. The list of experimental conditions for the single factor experiment.

\begin{tabular}{cccccc}
\hline Variable Factors & $\mathbf{1}$ & $\mathbf{2}$ & $\mathbf{3}$ & $\mathbf{4}$ & Other Factors \\
\hline Temperature $\left({ }^{\circ} \mathrm{C}\right)$ & 25 & 40 & 55 & 70 & Condition a \\
Oil sands to solvent ratio & $1: 1$ & $1: 5$ & $1: 10$ & $1: 20$ & Condition b \\
Stirring rate $(\mathrm{rpm})$ & 100 & 300 & 500 & 700 & Condition c \\
Stirring time $(\mathrm{min})$ & 20 & 40 & 60 & 80 & Condition d \\
Ultrasound time $(\mathrm{min})$ & 0 & 30 & 60 & 120 & Condition e \\
\hline
\end{tabular}

Table 2. The detailed description for conditions a, b, c, d, e in Table 1 .

\begin{tabular}{cccccc}
\hline Condition & $\begin{array}{c}\text { Temperature } \\
\left({ }^{\circ} \mathbf{C}\right)\end{array}$ & $\begin{array}{c}\text { Oil Sands to } \\
\text { Solvent Ratio }\end{array}$ & $\begin{array}{c}\text { Stirring Rate } \\
(\mathbf{r p m})\end{array}$ & $\begin{array}{c}\text { Stirring Time } \\
(\mathbf{m i n})\end{array}$ & $\begin{array}{c}\text { Ultrasound } \\
\text { Time }\end{array}$ \\
\hline $\mathrm{m}$ (min)
\end{tabular}

\subsection{Single Solvent Extraction and Composite Solvent Extraction}

The optimum technical conditions for bitumen recovery from crude bitumen samples by toluene were as follows: the temperature was $40^{\circ} \mathrm{C}$, crude bitumen sample to solvent ratio was 1:10, stirring rate was $500 \mathrm{rpm}$, stirring time was $60 \mathrm{~min}$, ultrasound time was $30 \mathrm{~min}$. Other solvents (n-heptane, tetrahydrofuran, cyclohexane, cyclopentane, ethyl acetate, n-pentane) were used to extract bitumen from crude bitumen samples at the optimum conditions, and the extraction process was repeated twice, as described in Section 2.2.

The composite solvents, including toluene/n-heptane, cyclohexane/cyclopentane, tetrahydrofuran/n-pentane, toluene/ethyl acetate, toluene/tetrahydrofuran, cyclohexane/ethyl acetate, and toluene/cyclohexane, were used to extract bitumen from crude bitumen samples at the optimum conditions. All of the composite solvents were mixed at a ratio of 1:1, and then the composite solvents were used to extract bitumen from crude bitumen samples.

\subsection{SARA Analysis}

The four bitumen fractions (SARA) were identified as important properties of bitumen quality, and the SARA content differences influenced the bitumen recovery. In this study, the four fractions were carried out using ASTM D4124. The bitumen from single solvent extraction and composite solvent extraction were all analyzed by ASTM D4124. Asphaltene was the component that could dissolve into toluene, but could not dissolve into n-heptane [25]. First, $2.0 \mathrm{~g}$ bitumen was put into a $500 \mathrm{~mL}$ beaker, $100 \mathrm{~mL}$-heptane was added, and the bitumen was sonicated at $50{ }^{\circ} \mathrm{C}$ for $1 \mathrm{~h}$. The mixture was centrifuged and the supernatant was transferred to a $500 \mathrm{~mL}$ flask. The insoluble solids were put into another flask. The process was repeated with $100 \mathrm{~mL}$-heptane until the supernatant was colorless. The insoluble solids were then dried and identified as asphaltene. The supernatant was placed under a rotary evaporator to obtain the mixtures (saturates, aromatics, and resins). The mixtures were eluted with different solvents following the literature [31].

\subsection{Viscosity Measurement and Element Content Analysis}

The viscosity of bitumen, by single and composite solvent extraction from crude bitumen samples, was measured by a viscometer (NDJ-5S, Shanghai Youyi Instrument Co. Ltd., Shanghai, China). The bitumen temperature was $50^{\circ} \mathrm{C}$. In the viscosity measurement, the relationship between bitumen 
viscosity and bitumen recovery was studied. The element content of bitumen from single solvent extraction and composite solvent extraction was analyzed by an elemental analyzer (vario micro cube, Elementar, Langenselbold, Germany), and the $\mathrm{C}, \mathrm{H}, \mathrm{O}, \mathrm{N}, \mathrm{S}$ element contents in different bitumen samples were measured.

\section{Results and Discussion}

\subsection{Single Factor Experiment}

The bitumen recovery increased quickly with increasing temperatures from 25 to $55^{\circ} \mathrm{C}$ (black line). The increasing temperature caused the rate of bitumen dissolving into toluene to increase, which caused the bitumen recovery to increase. The bitumen recovery decreased when the temperature increased from 55 to $70{ }^{\circ} \mathrm{C}$, due to the volatilization of toluene and the higher temperature influence on the bitumen recovery. The bitumen recoveries at $40,55{ }^{\circ} \mathrm{C}$ were $96.5 \mathrm{wt} \%, 97.2 \mathrm{wt} \%$. The bitumen recovery increase was low, so $40{ }^{\circ} \mathrm{C}$ was the optimal temperature.

The bitumen recovery increased from 88.2 to $96.5 \mathrm{wt} \%$ with the crude bitumen sample to solvent ratio increasing from 1:1 to 1:10 (red line). This is because the bitumen dissolution increases as the toluene content increases. The bitumen recovery increased $0.7 \mathrm{wt} \%$ when the toluene increased from 1:10 to 1:20. Thus, 1:10 was the optimal ratio.

The bitumen recovery initially increased after $100 \mathrm{rpm}$, and then reached a plateau as the stirring rate increased to $500 \mathrm{rpm}$ (green line). This indicated that $100 \mathrm{rpm}$ was the threshold stirring rate for the dissolution of bitumen in the organic solvent. The increasing stirring rate helped bitumen liberate from the minerals and dissolve into the toluene phase, though the bitumen recovery decreased $0.3 \mathrm{wt} \%$ as the stirring speed increased from 500 to $700 \mathrm{rpm}$. This was due to the increasing stirring rate influencing the SARA of bitumen, and then decreasing the bitumen recovery. Therefore, $500 \mathrm{rpm}$ was the optimal stirring rate.

The bitumen recovery increased greatly when the stirring time increased from 20 to $60 \mathrm{~min}$ (yellow line) because the bitumen recovery process dissolved into toluene. The increased stirring time caused the bitumen dissolution to increase; however, when the stirring time increased from $60 \mathrm{~min}$ to $80 \mathrm{~min}$, the bitumen recovery increased just $0.6 \mathrm{wt} \%$. Therefore, $60 \mathrm{~min}$ was the optimal stirring time.

Figure 3e shows that bitumen recovery increased from 95.5 to $96.5 \mathrm{wt} \%$ when the ultrasound time increased from 0 to $30 \mathrm{~min}$, because ultrasound promoted the bitumen dissolution process. The bitumen recovery decreased when the ultrasound time was higher than $30 \mathrm{~min}$, which was due to the ultrasound cavitation effect influencing the mixture stability. Therefore, $30 \mathrm{~min}$ was the optimal ultrasound time.

In order to obtain a higher bitumen recovery by toluene, the optimal operation condition was as follows: the temperature was $40^{\circ} \mathrm{C}$, crude bitumen sample to solvent ratio was $1: 10$, stirring rate was $500 \mathrm{rpm}$, stirring time was $60 \mathrm{~min}$, and ultrasound time was $30 \mathrm{~min}$. The process parameters were used for the next single solvent extraction and composite solvent extraction. 

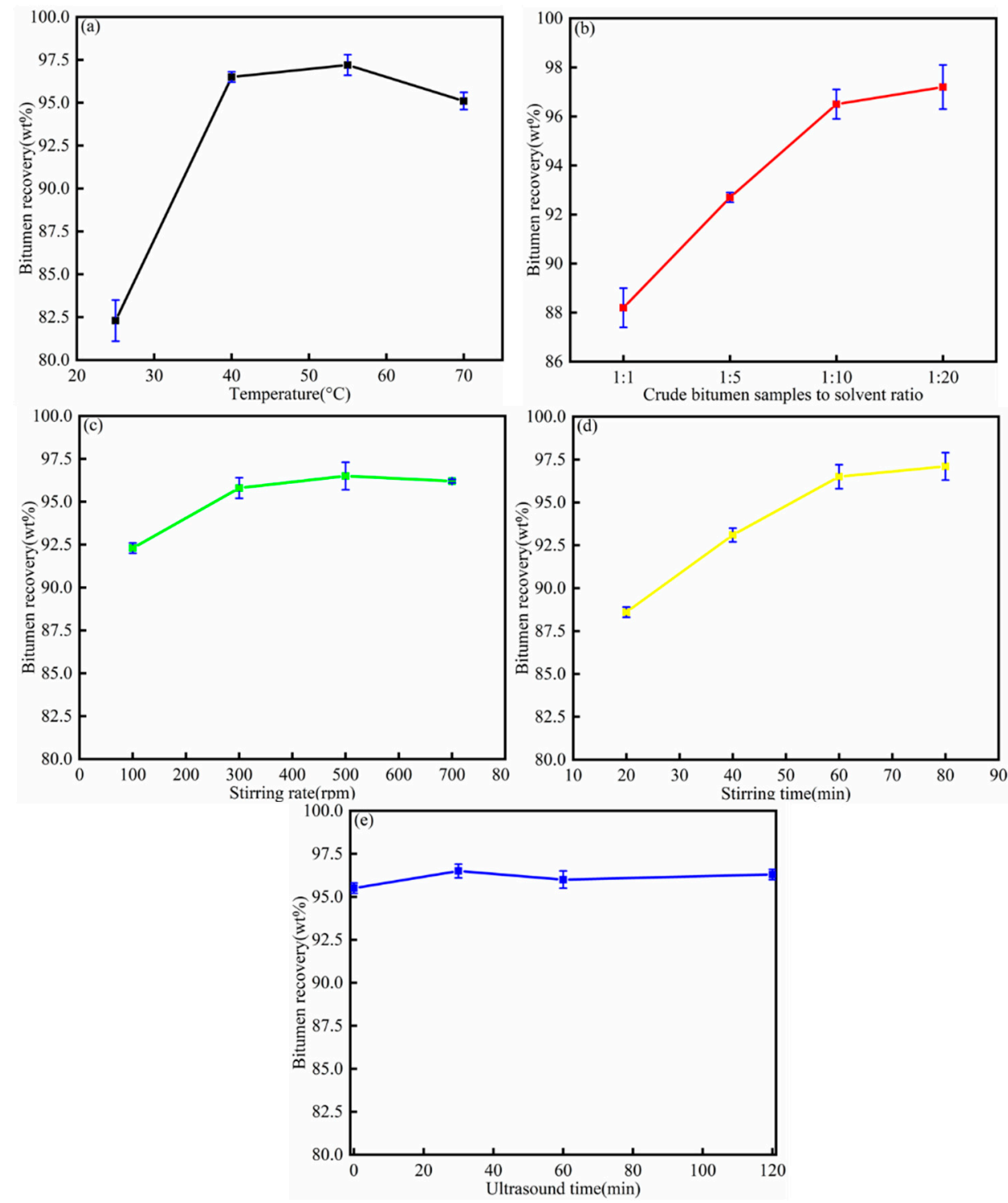

Figure 3. Influence of (a) temperature (black line), (b) crude bitumen sample to solvent ratio (red line), (c) stirring rate (green line), (d) stirring time (yellow line), and (e) ultrasound time (blue line) on the bitumen recovery from crude bitumen samples.

\subsection{Single Solvent Extraction Experiment}

The varying solvent extractions of bitumen were applied to study the effects of different solvents on bitumen recovery from crude bitumen samples, as shown in Figure 4. It was shown that the final bitumen recovery could reach at least $77.4 \%$ by $n$-heptane. Because $n$-heptane cannot dissolve asphaltene in bitumen, it could only dissolve the SAR (saturates, aromatics, and resins) components. Toluene showed the highest bitumen recovery $(96.5 \mathrm{wt} \%$ ) among these solvents, because it is an aromatic solvent that can dissolve bitumen components efficiently. Cyclohexane and cyclopentane obtained 87.2 and $88.4 \mathrm{wt} \%$ bitumen from crude bitumen samples, because cyclohexane and cyclopentane are cycloalkanes which are similar to the structure of aromatics and resins. When toluene or cycloalkanes were taken as solvents, most of the heavy components (e.g., resins and asphaltenes) could be dissolved into the solvent. However, for n-alkanes, bitumen heavy substances could not easily be extracted, so the bitumen recovery was low. Tetrahydrofuran, ethyl acetate, and n-pentane showed bitumen recovery among the toluene and n-heptane. Although toluene showed the highest bitumen recovery 
from crude bitumen samples, the toxicity of toluene limited the application. Therefore, finding an alternative solvent is a significant issue.

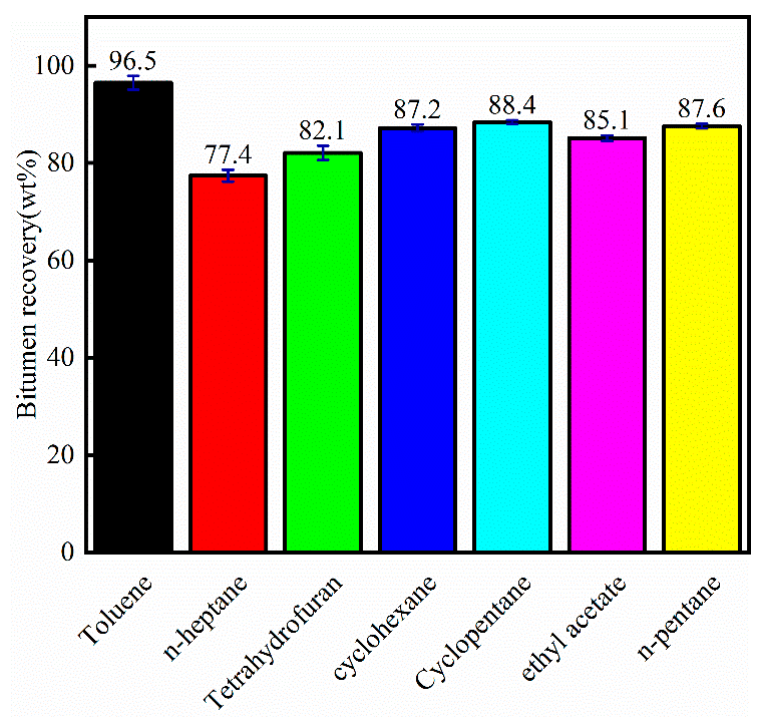

Figure 4. Final bitumen recovery by different solvents for crude bitumen samples.

Figure 5 indicates that increasing extraction times increase bitumen recovery. For different solvents, the influence of extraction time on bitumen recovery was varied. Bitumen recovery by toluene increased from $87.6 \mathrm{wt} \%$ (first extraction) to $93.4 \mathrm{wt} \%$ (second extraction), and the final bitumen recovery was $96.5 \mathrm{wt} \%$, which is higher than other solvents. The final bitumen recovery by different solvents was in the order of toluene $>$ cyclopentane $>$ n-pentane $>$ cyclohexane $>$ ethyl acetate $>$ tetrahydrofuran $>$ n-heptane. The first bitumen recovery order was toluene $>$ cyclopentane $>$ ethyl acetate $>$ cyclohexane $>$ n-pentane $>$ tetrahydrofuran $>$ n-heptane. The second bitumen recovery order was toluene $>$ n-pentane $>$ cyclopentane $>$ cyclohexane $>$ ethyl acetate $>$ tetrahydrofuran $>$ n-heptane. For different extraction times, the bitumen recovery orders were different.

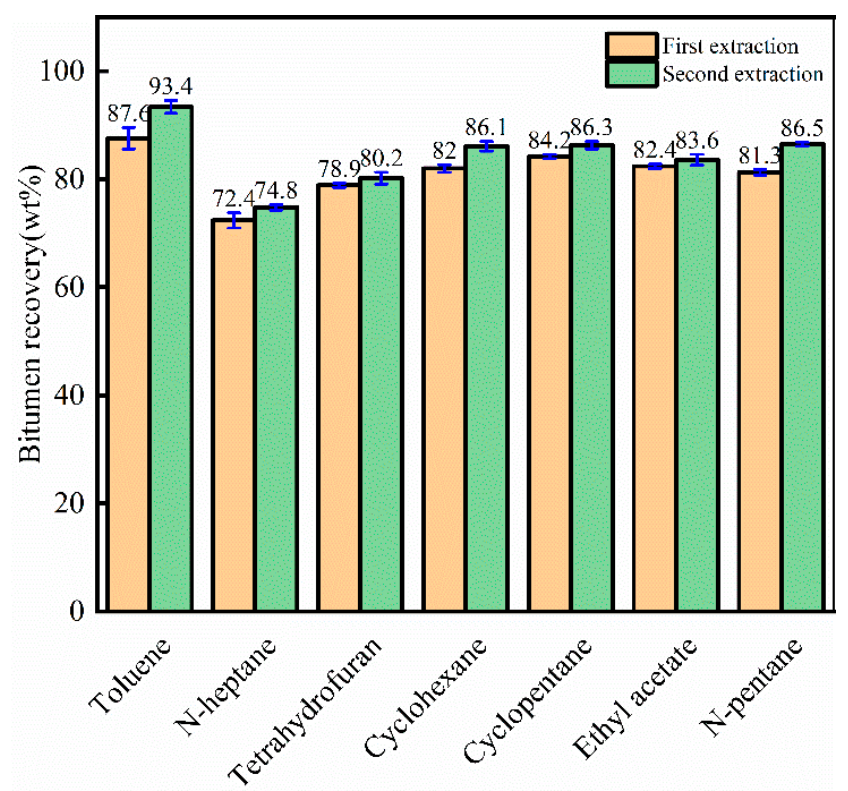

Figure 5. First and second bitumen recoveries by different solvents for crude bitumen samples. 


\subsection{SARA Analysis of Bitumen from Single Solvent Extraction}

Figure 6 shows the SARA contents of bitumen by different single solvent extractions. For saturates and aromatics, n-heptane and n-pentane showed high contents compared to other solvents, as shown in Figure $6 \mathrm{a}, \mathrm{b}$. The linear hydrocarbon dissolved the light components of bitumen. The bitumen by toluene extraction showed low saturate and aromatic contents, so the toluene dissolution of light components was low. The resin contents by n-heptane and n-pentane extraction were 26.9 and $23.4 \mathrm{wt} \%$, which were higher than those obtained by toluene extraction (Figure $6 \mathrm{c}$ ). These results indicate that linear hydrocarbons have a good solubilization with resins. The resin contents by toluene extraction showed the lowest bitumen recovery, which meant that toluene could not dissolve resin well. As shown in Figure $6 \mathrm{~d}$, the asphaltene content decreased from 23.2 to $0 \mathrm{wt} \%$ when the solvent was changed from toluene to n-heptane. Toluene was the aromatic solvent that showed the highest asphaltene content $(23.2 \mathrm{wt} \%)$ among the solvents. The asphaltene content of the bitumen extracted by n-heptane was $0 \mathrm{wt} \%$, because asphaltene is defined as the component that is insoluble in n-heptane but soluble in toluene. N-pentane obtained $6.5 \mathrm{wt} \%$ asphaltene. These results indicate that linear hydrocarbons do not have a good solubilization with asphaltene. The asphaltene contents obtained by tetrahydrofuran, cyclohexane, cyclopentane, and ethyl acetate extraction were $18.6,15.4,12.8$, and $11.7 \mathrm{wt} \%$, respectively.
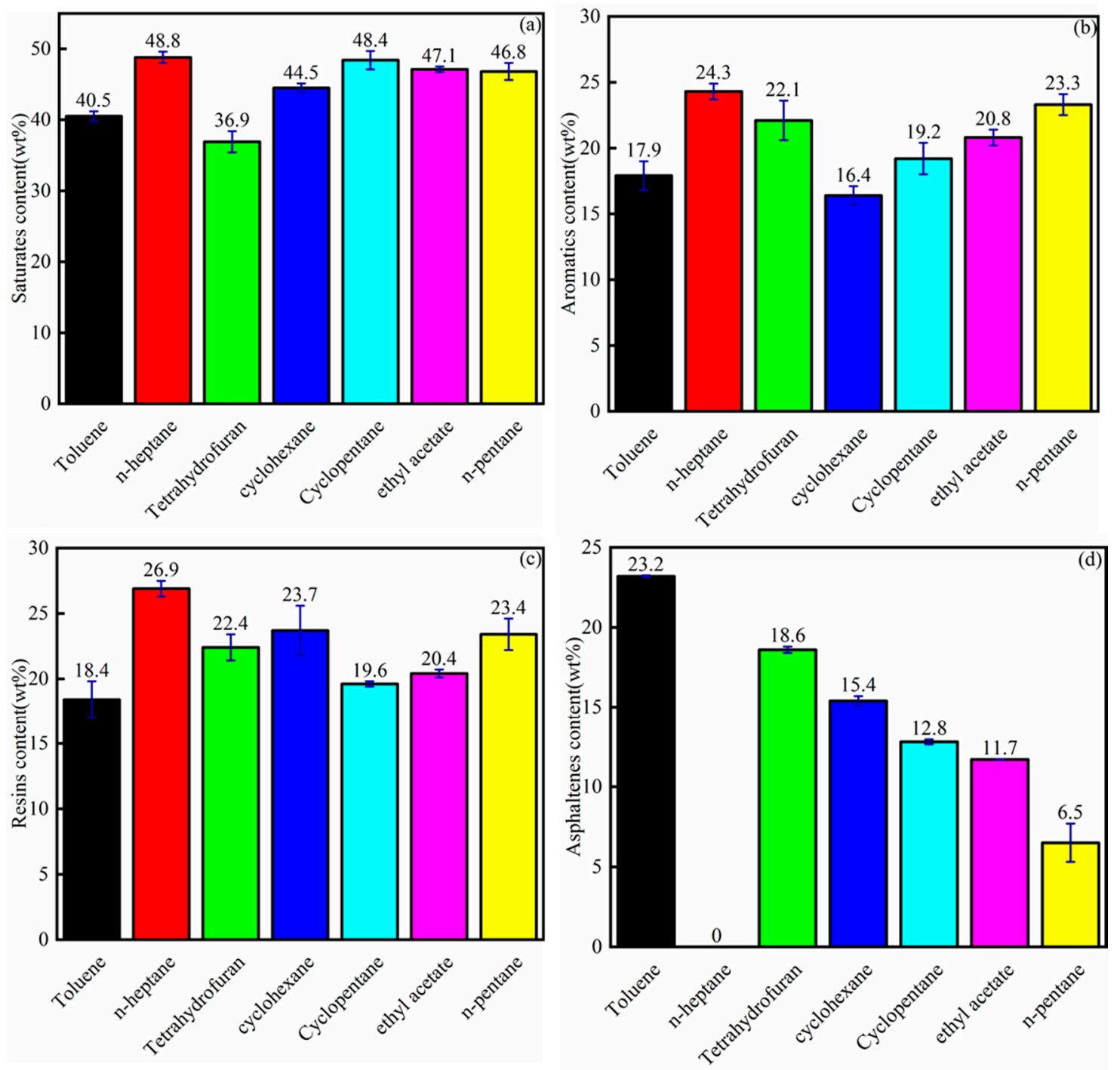

Figure 6. Saturates (a), aromatics (b), resins(c) and asphaltenes (d) contents of the bitumen from different single solvent extraction experiments. 
As shown in Figures 4 and 6, toluene showed the highest bitumen recovery, but the bitumen (extracted by toluene) composition contained low saturate, aromatic, and resin contents. The asphaltene content obtained by toluene extraction was the highest. The dissolution of asphaltene by the solvent indicated the ability to obtain bitumen.

\subsection{Composite Solvent Extraction}

As shown in Figure 7, the bitumen recovery increased significantly by composite solvent compared to the single solvent. In Figure 4, bitumen recovery was lower than $90 \mathrm{wt} \%$ (toluene exempt). In Figure 7, bitumen recovery was higher than $90 \mathrm{wt} \%$ (tetrahydrofuran/n-pentane exempt). The highest bitumen recovery for composite solvent was $98.9 \mathrm{wt} \%$ (toluene/cyclohexane) because toluene could dissolve the asphaltene component and cyclohexane could dissolve SAR components. Therefore, the toluene/cyclohexane composite solvent showed the highest bitumen recovery.

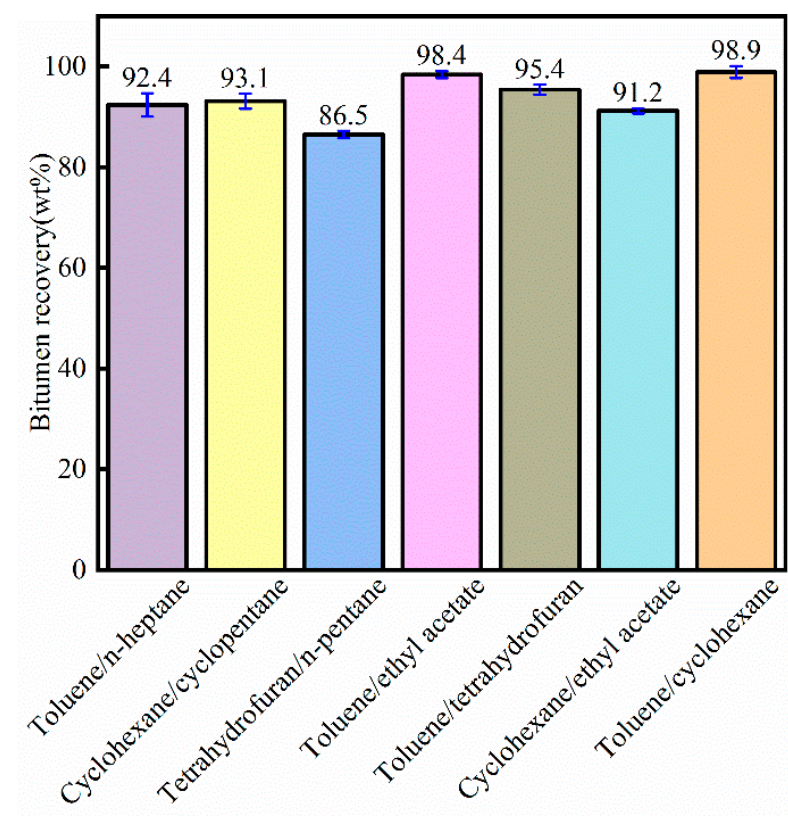

Figure 7. Bitumen recovery by composite solvents for crude bitumen samples.

The bitumen recovery extracted by composite solvents including toluene, namely toluene/n-heptane, toluene/ethyl acetate, toluene/tetrahydrofuran, and toluene/cyclohexane, was higher than the bitumen extracted by single solvent extraction.

\subsection{SARA Analysis of Bitumen from Composite Solvent Extraction}

Figure 8 shows the relative contents of SARA fractions of bitumen from different composite solvent extractions. As shown in Figures $6 \mathrm{~d}$ and $8 \mathrm{~d}$, the asphaltene content increased significantly from single solvent extraction to composite solvent extraction.

Among the composite solvents, toluene/cyclohexane showed the highest asphaltene content, while tetrahydrofuran/n-pentane showed the lowest asphaltene content. During the extraction process, the asphaltene content was closely related to the bitumen recovery. The higher the asphaltene content, the higher the bitumen recovery. 

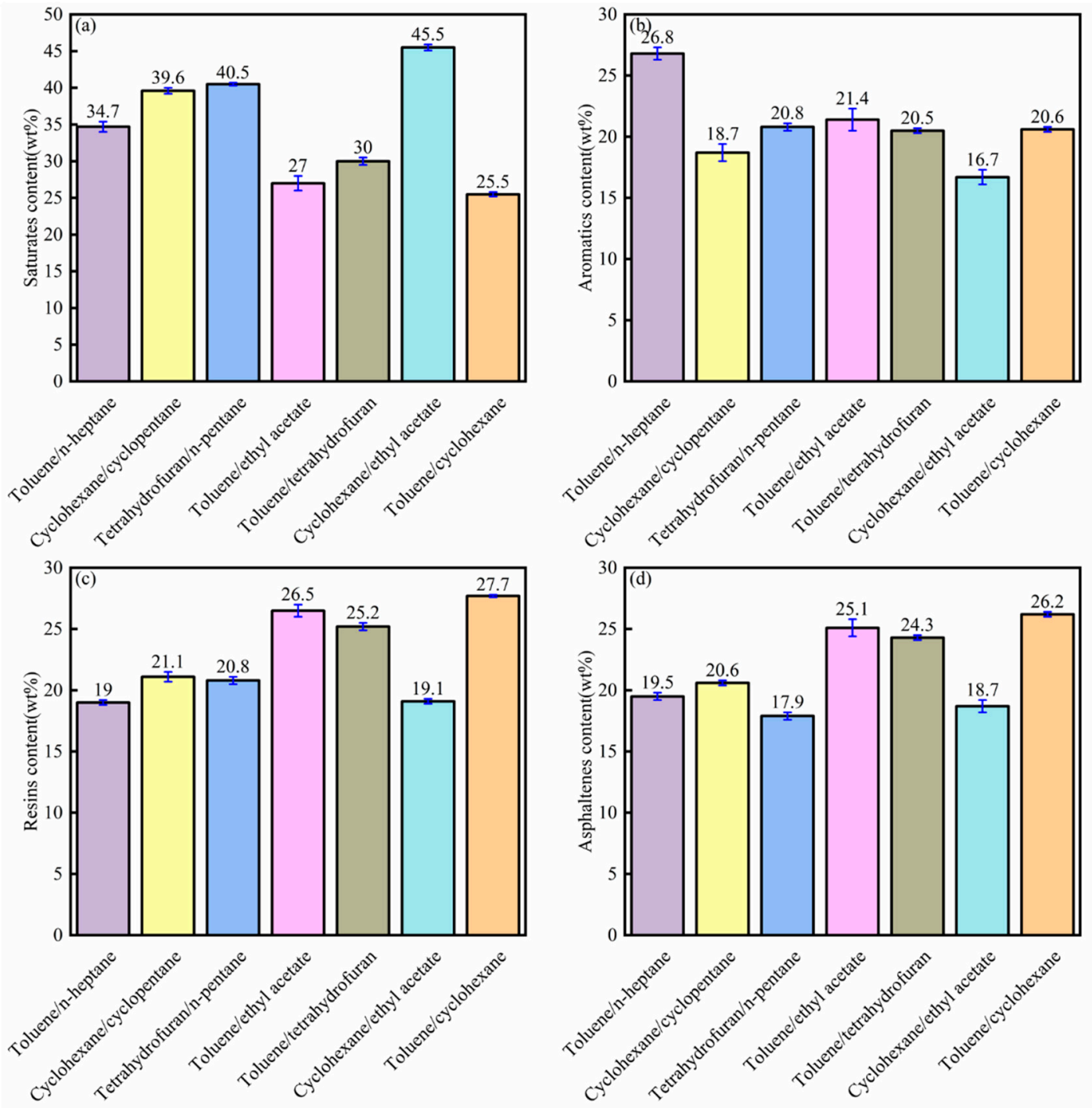

Figure 8. Saturate (a), aromatic (b), resin, and (c) asphaltene (d) contents of the bitumen from different composite solvent extraction experiments.

\subsection{Viscosity Analysis}

The bitumen samples that were extracted from different solvents showed different viscosities. The low bitumen viscosity helped liberate bitumen from minerals. Figure 9a indicates that the bitumen extracted from toluene showed the lowest viscosity (110 Pa.s), and the bitumen extracted from n-heptane showed the highest viscosity (234 Pa.s). Toluene dissolved the heaviest component (asphaltenes), so the viscosity decreased. The cyclic hydrocarbons (cyclohexane and cyclopentane) showed low viscosities (160 and $142 \mathrm{~Pa} \cdot \mathrm{s}$ ). The bitumen viscosity decreased significantly according to the composite solvent, as shown in Figure 9b. The lower the bitumen viscosity, the higher the bitumen recovery. Bitumen is a non-Newtonian fluid, and the relationship between the shearing force and shear rate was not linear. Bitumen mixtures showed linear viscoelastic properties under low temperatures and small deformations, but showed nonlinear viscoelastic properties under high temperatures and large deformations. Many researchers have focused on the mechanical properties of bitumen $[29,30]$. Bazzaz put forward a straightforward procedure to characterize the nonlinear viscoelastic response of asphalt concrete at high temperatures [29]. Darabi put forward a new model that could accurately describe the asphalt material behavior under different loading paths, and this model can help in experiment design [30]. 

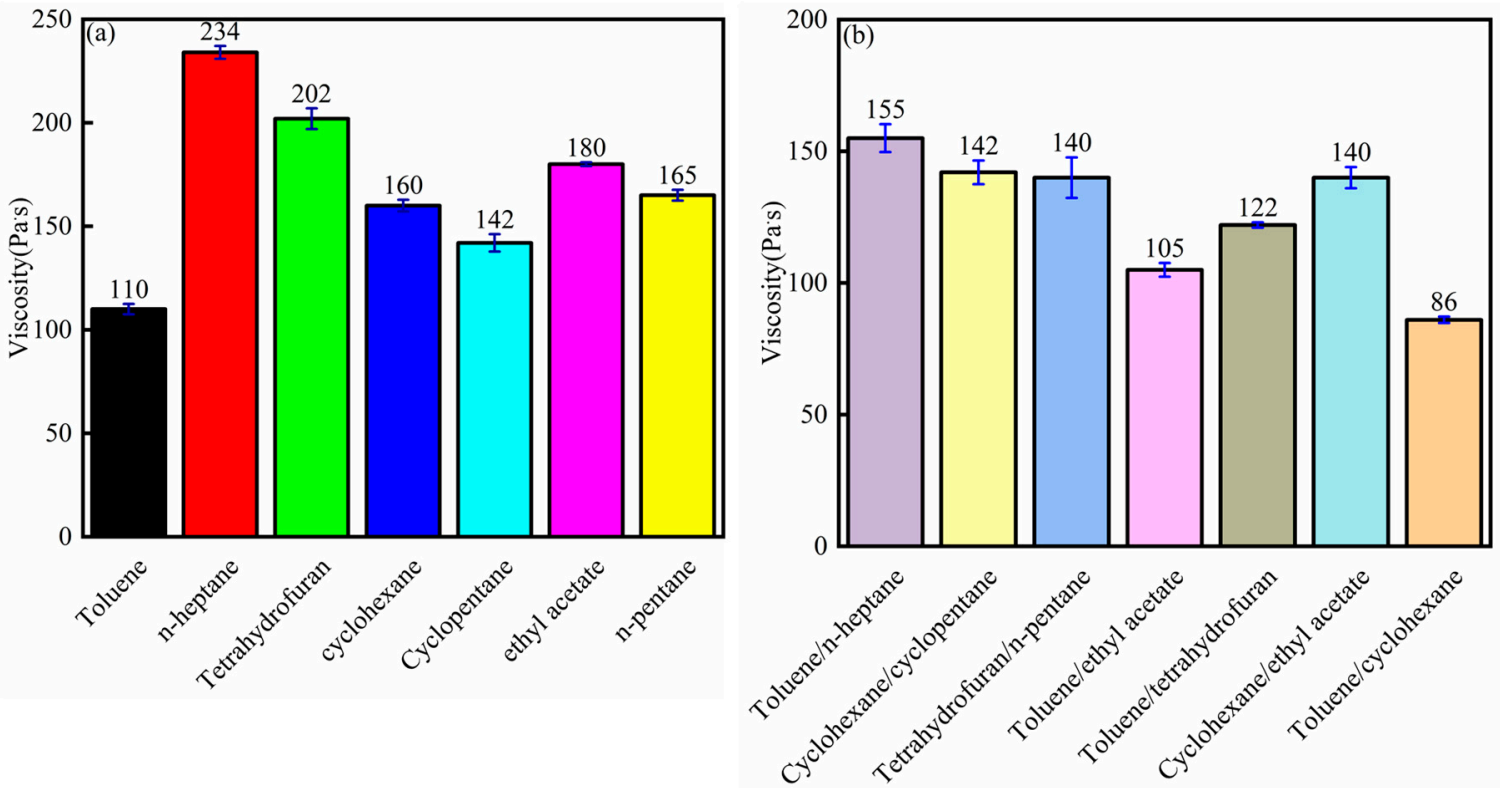

Figure 9. Viscosity analysis of bitumen from (a) single solvent extraction; (b) composite solvent extraction.

\subsection{The Element Content Analysis of Bitumen}

As shown in Table 3, the bitumen by toluene extraction showed the highest $\mathrm{C} / \mathrm{H}$ ratio, while bitumen by the $\mathrm{n}$-heptane extraction showed the lowest $\mathrm{C} / \mathrm{H}$ ratio. This was due to the fact that toluene could dissolve heavy components (asphaltene), and the $\mathrm{C} / \mathrm{H}$ in asphaltene is higher than the ratios in other components; meanwhile, $\mathrm{n}$-heptane could only dissolve the SAR components. The $\mathrm{C} / \mathrm{H}$ ratio for different solvents was different, which influenced bitumen recovery. The $\mathrm{C}$ content extracted by composite solvent was higher than that extracted by the single solvent, as shown in Table 4. The highest $\mathrm{C} / \mathrm{H}$ ratio was achieved by toluene/cyclohexane extraction. The higher the $\mathrm{C} / \mathrm{H}$ ratio, the higher the bitumen recovery.

Table 3. The elemental analysis of bitumen (wt \%) from single solvent extraction.

\begin{tabular}{cccccc}
\hline Bitumen from Single Solvent Extraction & $\mathbf{C}$ & $\mathbf{H}$ & $\mathbf{O}$ & $\mathbf{N}$ & $\mathbf{S}$ \\
\hline toluene & 83.358 & 9.650 & 0.072 & 0.490 & 6.430 \\
n-heptane & 79.652 & 12.152 & 2.766 & 0.347 & 5.083 \\
tetrahydrofuran & 81.642 & 11.048 & 2.623 & 0.322 & 4.365 \\
cyclohexane & 82.658 & 10.346 & 0.028 & 0.432 & 6.536 \\
cyclopentane & 82.356 & 10.586 & 1.481 & 0.440 & 5.137 \\
ethyl acetate & 81.568 & 11.036 & 2.874 & 0.354 & 4.168 \\
n-pentane & 82.265 & 10.952 & 1.057 & 0.406 & 5.320 \\
\hline
\end{tabular}

Table 4. The elemental analysis of bitumen ( $\mathrm{wt} \%)$ from composite solvent extraction.

\begin{tabular}{cccccc}
\hline Bitumen from Composite Solvent Extraction & $\mathbf{C}$ & $\mathbf{H}$ & $\mathbf{O}$ & $\mathbf{N}$ & $\mathbf{S}$ \\
\hline toluene/n-heptane & 83.532 & 10.564 & 0.442 & 0.379 & 5.083 \\
cyclohexane/cyclopentane & 83.048 & 10.298 & 1.509 & 0.265 & 4.889 \\
tetrahydrofuran/n-pentane & 82.653 & 11.892 & 0.662 & 0.336 & 4.458 \\
toluene/ethyl acetate & 84.685 & 8.780 & 0.455 & 0.405 & 5.675 \\
toluene/tetrahydrofuran & 84.068 & 9.365 & 0.094 & 0.376 & 6.097 \\
cyclohexane/ethyl acetate & 82.964 & 11.068 & 0.021 & 0.983 & 4.964 \\
toluene/cyclohexane & 85.026 & 8.460 & 0.803 & 0.344 & 5.367 \\
\hline
\end{tabular}




\section{Conclusions}

This research put forward a new method to solve the heterogeneous formation of bitumen occurring during the oil-gas drilling process. In order to alleviate the deterioration of drilling fluid performances caused by the formation of bitumen and to eliminate the negative influence of bitumen adhesion in time, we studied the solvent extraction process from crude bitumen samples taken from Halfaya oilfield (Iraq). The relation between the solvent and bitumen was analyzed. It was concluded that:

(1) The optimal operation condition for bitumen recovery by toluene from crude bitumen samples was, as follows: the temperature was $40{ }^{\circ} \mathrm{C}$, crude bitumen sample to solvent ratio was 1:10, stirring rate was $500 \mathrm{rpm}$, stirring time was $60 \mathrm{~min}$, ultrasound time was $30 \mathrm{~min}$.

(2) The bitumen recovery increased significantly using the composite solvent compared to the single solvent. The highest bitumen recovery from crude bitumen samples was $98.9 \mathrm{wt} \%$. SARA analysis indicated that the asphaltene content increased significantly from the single solvent to composite solvent. Toluene and cycloalkane showed the highest asphaltene content, while the n-alkanes showed the lowest asphaltene content. The composite solvent obtained the highest asphaltene content and bitumen recovery.

(3) The bitumen samples extracted from different solvents showed different viscosities. The bitumen viscosity influenced the bitumen recovery, and the lower the bitumen viscosity, the higher the bitumen recovery. The $\mathrm{C} / \mathrm{H}$ ratio of the bitumen followed this rule.

Author Contributions: Conceptualization-Y.L., Z.Q.; methodology-Y.L., H.Z.; validation-Z.N., W.H.; investigation-J.L., Y.L.; data curation-X.Z., Y.L.; writing-Y.L., H.Z.; funding acquisition-Z.Q., Z.N.

Funding: This work was financially supported by the 13th Five-Year Plan National Key Project of China (No.2017ZX05005005-006), the National Science and Technology Major Project of China (No.2017ZX05032-004-005, No.2017ZX05030-001), the National Natural Science Foundation of China (No.51704322), the Natural Science Foundation of Shandong Province, China (No. ZR2017QEE011), and the Shandong Province Key R \& D Plan, China (No.2018GSF116008).

Conflicts of Interest: The authors declare no conflict of interest.

\section{References}

1. Han, G.; Osmond, J.; Zambonini, M. A USD 100 million "Rock": Bitumen in the deepwater Gulf of Mexico. SPE Drill. Completion 2010, 25, 290-299. [CrossRef]

2. Arseniuk, S.E.; Becker, D.L.; Barrett, K.R.; Keller, D. Drilling Challenges in the bitumen saturated Grosmont formation. In Proceedings of the Canadian International Petroleum Conference, Calgary, AB, Canada, 16-18 June 2009; Petroleum Society of Canada: Calgary, AB, Canada, 2009.

3. Romo, L.; Shaughnessy, J.; Lisle, E. Challenges associated with Subsalt Tar in the Mad Dog Field. In Proceedings of the SPE Annual Technical Conference and Exhibition, Anaheim, CA, USA, 11-14 November 2007; Society of Petroleum Engineers: Richardson, TX, USA, 2007.

4. Ezeakacha, C.P.; Salehi, S.; Hayatdavoudi, A. Experimental Study of Drilling Fluid's Filtration and Mud Cake Evolution in Sandstone Formations. J. Energy Resour. Technol. 2017, 139, 022912. [CrossRef]

5. Perez, G. Development of a Chemical Treatment for the Management of Wellbore Tar Adhesion. In Proceedings of the SPE International Thermal Operations and Heavy Oil Symposium, Calgary, AB, Canada, 1-3 November 2005; Society of Petroleum Engineers: Richardson, TX, USA, 2005.

6. Yin, S.; Tian, T.; Wu, Z. Developmental characteristics and distribution law of fractures in a tight sandstone reservoir in a low-amplitude tectonic zone, eastern Ordos Basin, China. Geol. J. 2019, 54, 1-16. [CrossRef]

7. Yin, S.; Zhao, J.; Wu, Z.; Ding, W. Strain energy density distribution of a tight gas sandstone reservoir in a low-amplitude tectonic zone and its effect on gas well productivity: A 3D FEM study. J. Pet. Sci. Eng. 2018, 170, 89-104. [CrossRef]

8. Chen, H.; Zhang, S.; Zhao, Z.; Liu, M.; Zhang, Q. Application of Dopamine Functional Materials in Water Pollution Control. Prog. Chem. 2019, 31, 571-579. 
9. He, L.; Lin, F.; Li, X.; Sui, H.; Xu, Z. Interfacial sciences in unconventional petroleum production: From fundamentals to applications. Chem. Soc. Rev. 2015, 44, 5446-5494. [CrossRef]

10. Nie, F.; He, D.; Guan, J.; Li, X.; Hong, Y.; Wang, L.; Zheng, H.; Zhang, Q. Oil sand pyrolysis: Evolution of volatiles and contributions from mineral, bitumen, maltene, and SARA fractions. Fuel 2018, 224, 726-739. [CrossRef]

11. Meng, M.; Qiu, Z.; Zhong, R.; Liu, Z.; Liu, Y.; Chen, P. Adsorption characteristics of supercritical $\mathrm{CO}_{2} / \mathrm{CH}_{4}$ on different types of coal and a machine learning approach. Chem. Eng. J. 2019, 368, 847-864. [CrossRef]

12. Schramm, L.L.; Smith, R.G.; Stone, J.A. A surface-tension method for the determination of anionic surfactants in hot water processing of athabasca oil sands. Colloids Surf. 1984, 11, 247-263. [CrossRef]

13. He, J.J.; Geng, A.S.; Wu, L.L. Effect of Lithology on the Efficiency of the Hot Water-Based Extraction for Oil Sand Bitumen: A Case Study on Oil Sands from Houba, Sichuan and Tumuji, Inner Mongolia. Bull. Mineral. Petrol. Geochem. 2015, 34, 379-386.

14. Khraisha, Y.H. Study of extraction and pyrolysis of Jordan tar sand. Int. J. Energy Res. 1999, 23, 833-839. [CrossRef]

15. Dai, Q.; Chung, K.H. Hot water extraction process mechanism using model oil sands. Fuel 1996, 75, $220-226$. [CrossRef]

16. Tong, W.; Chao, Z.; Zhao, R.; Zhu, C.; Yang, C.; Liu, C. Solvent Extraction of Bitumen from Oil Sands. Energy Fuels 2014, 28, 2297-2304.

17. Lin, F.; Stoyanov, S.R.; Xu, Y. Development, Recent Advances in Nonaqueous Extraction of Bitumen from Mineable Oil Sands: A Review. Org. Process Res. Dev. 2017, 21, 492-510. [CrossRef]

18. Ma, Y.; Li, S. The pyrolysis, extraction and kinetics of Buton oil sand bitumen. Fuel Process. Technol. 2012, 100, 11-15. [CrossRef]

19. Liu, P.; Zhu, M.; Zhang, Z.; Zhang, D. Pyrolysis of an Indonesian Oil Sand in a Thermogravimetric Analyser and a Fixed-Bed Reactor. J. Anal. Appl. Pyrolysis 2016, 117, 191-198. [CrossRef]

20. Wang, Q.; Jia, C.; Ge, J.; Guo, W. ${ }^{1} \mathrm{H}$ NMR and ${ }^{13} \mathrm{C}$ NMR Studies of Oil from Pyrolysis of Indonesian Oil Sands. Energy Fuels 2016, 30, 2478-2491.

21. He, D.M.; Nie, F.; Guan, J.; Hu, H.Q.; Zhang, Q.M. Hot Water Extraction and Fixed Bed Pyrolysis for Bitumen Recovery of an Indonesian Oil Sand. Appl. Mech. Mater. 2014, 672, 624-627. [CrossRef]

22. Zhou, Y.; Yin, D.; Chen, W.; Liu, B.; Zhang, X. A comprehensive review of emulsion and its field application for enhanced oil recovery. Energy Sci. Eng. 2019, 7, 1046-1058. [CrossRef]

23. Zhou, Y.; Yin, D.; Cao, R.; Zhang, C. The mechanism for pore-throat scale emulsion displacing residual oil after water flooding. J. Pet. Sci. Eng. 2018, 163, 519-525. [CrossRef]

24. Zhong, H.; Qiu, Z.; Chai, J.; Guo, B.; Dong, S.; Liu, J. A preliminary study of the preparation of shale stabilizer with oil sludge-from waste to resource. J. Pet. Sci. Eng. 2018, 161, 50-60. [CrossRef]

25. Li, X.; Hou, J.; Sui, H.; Sun, L.; Xu, L. Switchable-Hydrophilicity Triethylamine: Formation and Synergistic Effects of Asphaltenes in Stabilizing Emulsions Droplets. Materials 2018, 11, 2431. [CrossRef]

26. Clark, K.A.; Pasternack, D.S. Hot Water Seperation of Bitumen from Alberta Bituminous Sand. Ind. Eng. Chem. 1932, 24, 1410-1416. [CrossRef]

27. Alvarez-Majmutov, A.; Gieleciak, R.; Chen, J. Modeling the molecular composition of vacuum residue from oil sand bitumen. Fuel 2019, 241, 744-752. [CrossRef]

28. Sitnov, S.A.; Vakhin, A.V.; Mukhamatdinov, I.I.; Onishchenko, Y.V.; Feoktistov, D.A. Effects of calcite and dolomite on conversion of heavy oil under subcritical condition. Pet. Sci. Technol. 2019, 37, 687-693. [CrossRef]

29. Bazzaz, M.; Darabi, M.K.; Little, D.N. A straightforward procedure to characterize nonlinear viscoelastic response of asphalt concrete at high temperatures. Transp. Res. Rec. 2018, 2672, 481-492. [CrossRef]

30. Darabi, M.K.; Huang, C.-W.; Bazzaz, M.; Masad, E.A.; Little, D.N. Characterization and validation of the nonlinear viscoelastic-viscoplastic with hardening-relaxation constitutive relationship for asphalt mixtures. Constr. Build. Mater. 2019, 216, 648-660. [CrossRef]

31. Li, X.; Lin, H.; Wu, G.; Sun, W.; Sui, H. Operational Parameters, Evaluation Methods, And Fundamental Mechanisms: Aspects of Nonaqueous Extraction of Bitumen from Oil Sands. Energy Fuels 2012, 26, 3553-3563. [CrossRef]

(C) 2019 by the authors. Licensee MDPI, Basel, Switzerland. This article is an open access article distributed under the terms and conditions of the Creative Commons Attribution (CC BY) license (http://creativecommons.org/licenses/by/4.0/). 